\title{
Mechanical Properties and Tribological Behaviour of Recycled Polyethylene/Cow Bone Particulate Composite
}

\author{
Agunsoye J. O. ${ }^{1}$, Talabi S. I. ${ }^{2}$, Awe O. ${ }^{3} \&$ Kelechi H. ${ }^{1}$ \\ ${ }^{1}$ Department of Metallurgical and Materials Engineering, University of Lagos, Nigeria \\ ${ }^{2}$ Department of Materials and Metallurgical Engineering, University of Ilorin, Nigeria \\ ${ }^{3}$ Department of Metallurgical Engineering, Yaba College of Technology, Nigeria \\ Correspondence: Agunsoye Johsnon Olumuyiwa, Department of Metallurgical and Materials Engineering, \\ University of Lagos, Nigeria. Tel: 234-808-302-1146. E-mail: jagunsoye@unilag.edu.ng
}

Received: December 15, 2012 Accepted: January 10, 2012 Online Published: January 28, 2013

doi:10.5539/jmsr.v2n2p41 URL: http://dx.doi.org/10.5539/jmsr.v2n2p41

\begin{abstract}
The effects of particulate cow bone additions on the mechanical properties and tribological behaviour of cow bone reinforced polyethylene composite was evaluated to assess the possibility of using it as a new material for engineering applications. Cow bone particles reinforced with recycled low density polyethylene (RLDPE) was prepared by varying the cow bone particles from $5-25 \mathrm{wt} \%$ with $5 \mathrm{wt} \%$ interval using compression method. The mechanical properties of the developed composite were investigated. Scanning electron Microscopy (SEM) was used to examine the surface morphology of the composites. Wear of the composites were conducted using pin on disc machine by varying speed, time and load. Factorial design experiment was conducted as per standard 1.8 orthogonal arrays, with a view to investigate which of the design parameters; speed, load and time most significantly affect the dry sliding wear on the composites. The results revealed that tensile strength and the hardness values of the composite increases with increased in $\mathrm{wt} \%$ cow bone particles while the impact strength and rigidity decreased. The study revealed that the additions of the particulate cow bone have the most significant main effect on the wear behaviour of the composite while the interactions between load and time has no significant. Hence, cow bone particles can be use to improve the strength and wear properties of RLDPE.
\end{abstract}

Keywords: cow bone, microstructure, mechanical properties, polyethylene and wear

\section{Introduction}

Many of our modern technologies require materials with usual combination of properties that cannot be met by the conventional metal alloys, ceramics, and polymeric materials. Composites, the wonder material with light-weight; high strength-to-weight ratio, stiffness properties and controlled aniosotropy have emerged as a major class of structural elements and are either used or being considered as substitutions for metals/traditional material like metals, wood etc. (Dhingra, 1986). Other advantages of composites are good corrosion resistance, impact resistance and fatigue strength. A unique feature of composites is that the characteristics of the finished product can be tailored to a specific engineering requirement by the careful selection of matrix and the reinforcement type. The use of polymers and polymer composites in various tribological situations has become state-of-the-art. Nevertheless, new developments are still under way to explore new fields of applications for these materials and to tailor their products for more extreme load conditions. Nowadays, there are more and more applications in which friction and wear are critical issues. Polymers containing different fillers and/or reinforcements are frequently used for these purposes. However, how these materials must exactly be designed depends on the requirement profile of the particular application. These means tribological characteristic i.e. the friction coefficient and the wear resistance are no real material properties, but depend on the system in which these materials have to function. Polymers reinforced with nanometre-sized fillers are recently under discussion because of some excellent properties they have shown under various testing conditions (Bahadur et al., 1992). Regarding to their wear resistance, not so many efforts have been undertaken so far towards the development of such materials. However, some results were achieved in various studies which give hint that this method is also promising for new processing route of wear resistance materials (Wang et al., 1996). Studies on polymer matrix composites subjected to sliding and abrasive wear indicate that wear resistance depends on the detailed properties of the material as well as the external wear conditions such as applied pressure and contact velocity 
(Friedrich, 1986). Researchers have shown that tribological behaviour of polymers may be improved by filling them with inorganic particulate compounds or fibers (Mohanty et al., 2000; Voss et al., 1985). The wear resistance of ultra-high molecular weight polyethylene has been found to be much higher than that of carbon steel and bronze in sliding friction, and than that of nylon-66, teflon, carbon steel, ceramic and enamel coating under such abrasive wear conditions as water-sand slurry or soil (Briscoe et al., 1986; Weston et al., 2010).

Ecological concerns have resulted in renewed interest in natural and compostable materials, and therefore issues such as biodegradability, the high rate of depletion of petroleum resources and new environmental safety regulations are becoming important. Public attention is now being placed on the environmentally gentle and friendly composite materials made from natural fillers and polymeric materials. It is the reason material components such as natural fibres, biodegradable polymers can be considered as 'interesting'-environmentally safe-alternatives for the development of new biodegradable composites (Saira et al., 2007; Aigbodion et al., 2011; Anil et al., 2010). As the population of the world increases, so do the number of cattle, and this in turn gives rise to one heck of big strange waste disposal problem, Nigeria in particular. At least one recycling method that was used in the past is no longer available, so billions of pounds of waste cow-bone has been classified as fit only for disposal, contributing to overburdened landfills and waste management problem. It is on the basis of this daunting challenge, that motivated research into the development of new eco-friendly, agro based products (cow bone).The purpose of the present study is to explore the potential of using cow-bone as reinforcement in polymer matrix composite to produce an alternative material that will be environmentally friendly, with improve wear resistance for possible applications such as automobile. To characterize the tribological behaviour of the composites, pin-on-disc test which is one of the most frequently used configurations was employed to determine the most important tribological property, the specific wear rate of the composite to be optimized.

\section{Experimental Procedures}

\subsection{Samples Preparations}

The fresh cow bones (limb bones) were collected from an abattoir in Lagos, Nigeria, washed and cleaned to a good physical condition. The cow bones were washed in ethanol to remove oil and dirt and were then dried in an electric furnace at $100{ }^{\circ} \mathrm{C}$ for 24 hours to ensure complete removal of the remaining oil constituent in the cow bone. The cow bones were grounded to fine particles with a pulverizing machine and then sieved to $106 \mu \mathrm{m}$.

Chemical analysis of the cow bone was done with Absorption Spectrometer (AAS) (see Table 1).

Table 1. Chemical composition of the cow bone

\begin{tabular}{cccccc}
\hline Metal & $\mathrm{Ca}$ & $\mathrm{Fe}$ & $\mathrm{Au}$ & $\mathrm{Sr}$ & $\mathrm{Sn}$ \\
\hline$\%$ Composition & 23.326 & 2.602 & $\mathrm{Nil}$ & $\mathrm{Nil}$ & $\mathrm{Nil}$ \\
\hline
\end{tabular}

Recycled low density polyethylene was shredded into small particle sizes, dried under sun, grinded and sintered in a sintering machine. The compounding of the polymer matrix with cow bone powder was done with a two roll mill machine at $150{ }^{\circ} \mathrm{C}$. The compounded polymer matrix samples produced were pressed after being wrapped with aluminium foil to avoid sticking for seven minutes in a pressing machine for 2 hours. Five samples with different percentages of cow bone particles ranging from 5 to $25 \mathrm{wt} \%$ were produced.

\subsection{Physical Test}

The densities of the dimensioned samples of known weight were determined using Equation 1. Initially weighed dried samples were placed in a beaker with water and reweighed at an interval of $24 \mathrm{hrs}$ for $168 \mathrm{hrs}$. The water absorption rate was then determined using Equation 2.

\subsection{Mechanical Test}

The hardness property of the samples was determined using Rockwell hardness tester under a load of $60 \mathrm{~kg}$. The impact energy of the samples was determined with a Charpy Impact Machine. Tensile test of the composites was carried out using the Hounsfield Tensometer Tensile Machine. The morphologies of the composites were observed by SEM.

$$
\rho=m / v
$$

where $\rho=$ density, $m=$ mass, $v=$ volume of sample

$$
\% \text { weight gained }=[(\text { final weight }- \text { initial weight }) \times 100] / \text { initial weight }
$$




\subsection{Wear Test}

A pin-on-disc test apparatus was used to investigate the dry sliding behaviour of the RLDPE composites as per ASTM G99-95 Standard (Pihtili et al., 2002). the disc used is En-32 steel hardened to $62 \mathrm{HRC}, 200 \mathrm{~mm}$ track diameter and $12 \mathrm{~mm}$ thick with surface roughness of $20 \mu \mathrm{m}$ Ra.

The initial weight of the sample was measured using a single pan electronic weighing scale with an accuracy of $0.0001 \mathrm{~g}$. During the test, the pin was pressed against the counter rotating steel disc. After running through a fixed distance, the sample was removed, cleaned with acetone, dried, and weighed to determine the weight loss due to wear. The differences in weight measure before and after gives the wear of the samples. The wear test was carried out with variable sliding speed, load and time shown in Table 2. The experimentations were conducted as per standard 1.8 orthogonal arrays, so as to investigate which of the design parameters significantly affect the dry sliding wear for the selected combinations of sliding speed, time and load. Factorial design and linear regression methods are common tools used in engineering analysis. These techniques consist of plan of experiments with objective of acquiring data in a controlled way, executing those experiments in order to obtain information about the behaviour of a given process (Aigbodion et al., 2011). Two levels of each of the three factors were entered in Table 3 and the treatment combinations for the two levels and three factors are tabulated in Table 4. The model equation was obtained by representing the wear rate value by $\mathrm{W}$, as a function of the process parameters below:

$$
W=f(S s, T t, L a, R r)
$$

Where (Ss) is the Sliding speed, (Tt) time, (La) load, and (Rr) is the reinforcer (particulate cow bone).

The model selected includes the effects of main variables first-order and second-order interactions of variables. Hence the general model is represented as:

$$
\begin{gathered}
W=\beta_{0}+\beta_{1} S s+\beta_{2} T t+\beta_{3} L a+\beta_{4} R r+\beta_{5} S s T t+\beta_{6} S s L a+\beta_{7} S s R r+\beta_{8} T t L a+\beta_{9} T t R r+\beta_{10} L a T t+ \\
\beta_{11} S s T t L a+\beta_{12} S s T t R r+\beta_{13} S s L a R r+\beta_{14} T t L a R r+\beta_{15} S s T t L a R r
\end{gathered}
$$

where $\beta_{0}$ is average response of $W$ and $\beta_{1}, \beta_{2}, \beta_{3}, \beta_{4}, \beta_{5}, \beta_{6}, \beta_{7}$ are coefficients associated with each variable $S s, L a$, $T t$ and interactions.

Table 2. Process parameters for the wear test

\begin{tabular}{cccc}
\hline Levels & Sliding speed $(\mathrm{m} / \mathrm{s})$ & Time $(\mathrm{s})$ & Load $(\mathrm{N})$ \\
\hline 1 & 1.18 & 60 & 10 \\
2 & 2.36 & 120 & 15 \\
\hline
\end{tabular}

Table 3. Statistical design of the wear process

\begin{tabular}{ccccc}
\hline Factor & Name & Units & Low level(-) & High level $(+)$ \\
\hline $\mathrm{Ss}$ & Speed & $\mathrm{m} / \mathrm{s}$ & 1.18 & 2.36 \\
$\mathrm{Tt}$ & Time & $\mathrm{Sec}$ & 60 & 120 \\
$\mathrm{La}$ & Load & $\mathrm{N}$ & 10 & 15 \\
$\mathrm{Rr}$ & Reinforcer & $\mathrm{Wt} \%$ & 10 & 25 \\
\hline
\end{tabular}

Table 4. Factorial design of the wear process showing treatment combinations

\begin{tabular}{cccc}
\hline Exp. number & Sliding speed level & $\begin{array}{c}\text { Load } \\
\text { level }\end{array}$ & $\begin{array}{c}\text { Time } \\
\text { level }\end{array}$ \\
\hline 1 & -1 & -1 & -1 \\
Ss & +1 & -1 & -1 \\
$\mathrm{La}$ & -1 & +1 & -1 \\
$\mathrm{SsLa}$ & +1 & +1 & -1 \\
$\mathrm{Tt}$ & -1 & -1 & +1 \\
$\mathrm{SsTt}$ & +1 & -1 & +1 \\
$\mathrm{LaTt}$ & -1 & +1 & +1 \\
SsLaSd & +1 & +1 & +1 \\
\hline
\end{tabular}




\section{Results and Discussion}

\subsection{Mechanical Properties of Cow Bone Reinforced Polymer Matrix Composite}

The tensile strength of the composites increases with increase in volume percent of the reinforcer (particulate cow bone) from $5.5 \times 10^{-1} \mathrm{MPa}$ for control sample with $0 \%$ reinforcer to a maximum value of $1.9 \mathrm{MPa}$ for $25 \%$ reinforcer in the RLDPE matrix (Figure 1). The low tensile strength is due to improper distribution of the filler with the matrix. Coupling agent such as PE-g-MAH (maleic anhydride) could be utilized for enhanced composite. The Young Modulus which is a measure of the rigidity of the sample is significantly affected by the reinforcer (particulate cow bone). As the reinforcer content increases the rigidity of the composite decreases (Figure 2). Also, the hardness values of the composites increase with increased in the $\mathrm{wt} \%$ of reinforcer (particulate cow bone) in the RLDPE composite. A rapid rise in hardness was observed beyond $15 \mathrm{wt} \%$ reinforcer (particulate cow bone) and a maximum $10.5 \mathrm{HB}$ was obtained for the sample with $25 \mathrm{wt} \%$ reinforcer (particulate cow bone) in the composites (Figure 3).

The impact energy of the composite decreases with increased in reinforcer addition (Figure 4). This might be due to crack propagation within the composite as a result of impact loading. Also, due to increase in particle size and filler loading, there is a reduction in total surface area available for matrix-filler interaction. This leads to increase in mobility of the matrix molecules. As a result of the increase of mobility of matrix molecule the particle sizes tends to accumulate, increase in which result into weakening of the interfacial bond between the matrix and the filler. It is therefore expected that as the filler content and particle size increases there will be a decrease in impact strength.

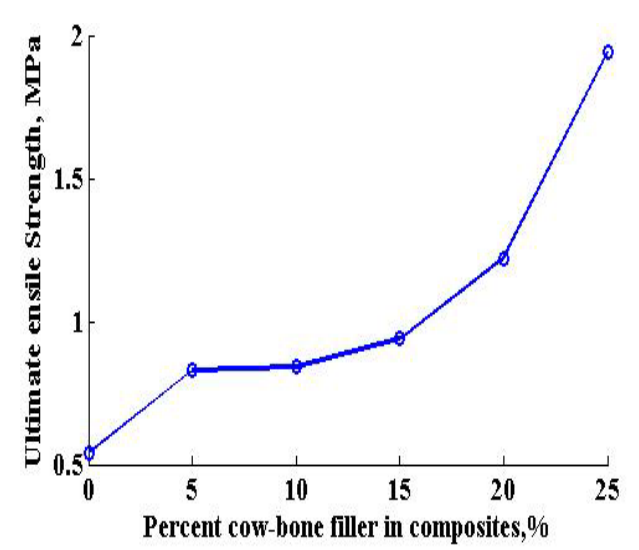

Figure 1. Effect of filler additions on the tensile strenghth of the composites

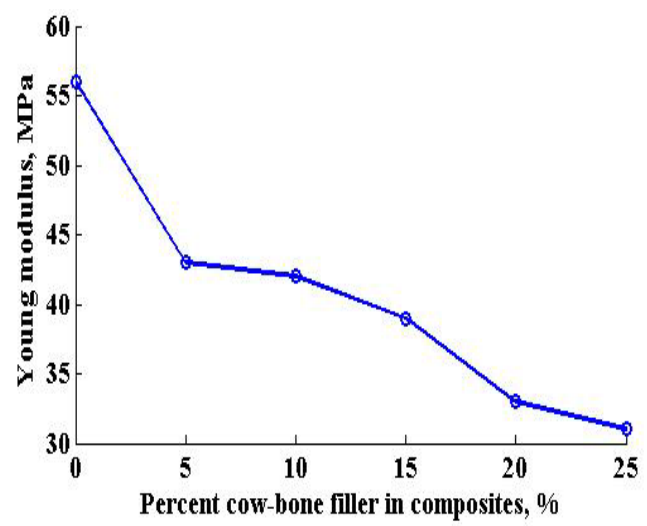

Figure 2. Effect of filler additions on the Young modulus of the composites 


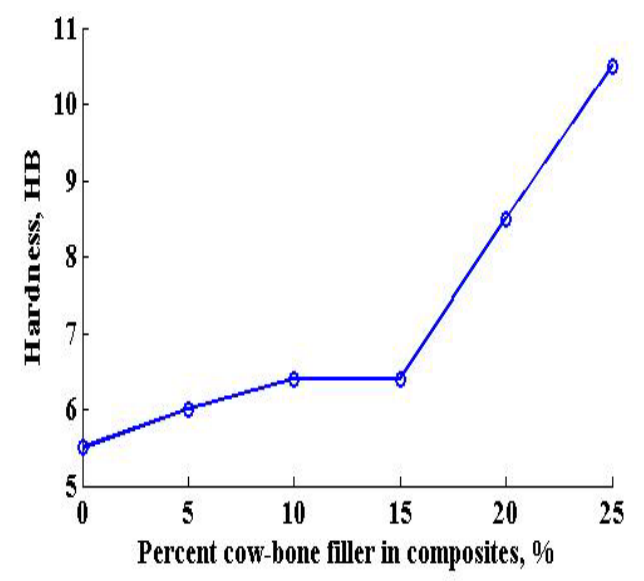

Figure 3. Effect of filler additions on the hardness of the composites

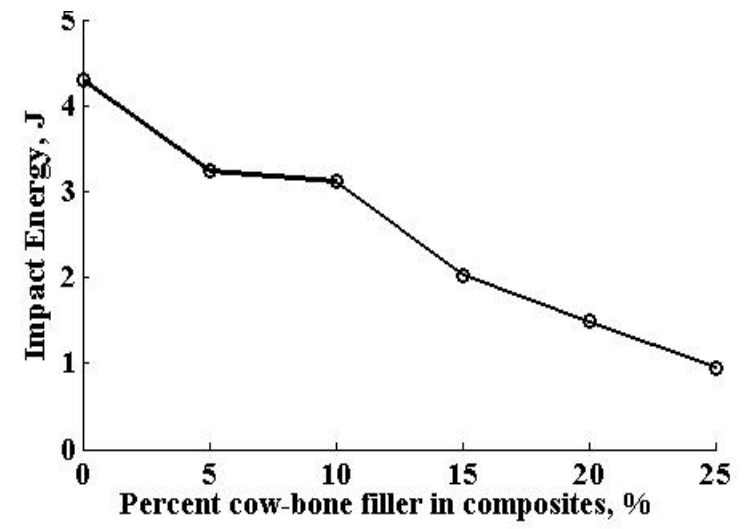

Figure 4. Effect of filler additions on the impact energy of the composites

\subsection{Physical Properties of HLDPE Composites}

The rate of water absorption by the composites over a period of 168 hours at an interval of 24 hours increased with increase in the $\mathrm{wt} \%$ of the particulate cow bone (Table 5). Reduced porosity was observed with increasing amount of cow bone reinforcement.

Table 5. Absorption rate of cow bone reinforced polyethylene composite

\begin{tabular}{ccccccc}
\hline \multicolumn{7}{c}{ Wt\% of Cow bone } \\
\hline Time (hrs) & $\mathbf{0 w t} \%$ & $\mathbf{5 w t} \%$ & $\mathbf{1 0 w t} \%$ & $\mathbf{1 5 w t} \%$ & $\mathbf{2 0 w t} \%$ & $\mathbf{2 5 w t} \%$ \\
\hline $\mathbf{2 4}$ & 0 & 0 & 0 & 0 & 0 & 0 \\
$\mathbf{4 8}$ & 0 & 0 & 0 & 0 & 0 & 0 \\
$\mathbf{7 2}$ & 0 & 0 & 5 & 6 & 8 & 9.1 \\
$\mathbf{9 6}$ & 5 & 6 & 6 & 9 & 11 & 12.1 \\
$\mathbf{1 2 0}$ & 6 & 6 & 9 & 11 & 12 & 15.2 \\
$\mathbf{1 4 4}$ & 6 & 6 & 9 & 11 & 12 & 18.2 \\
$\mathbf{1 6 8}$ & 6 & 6 & 9 & 11 & 15 & 18.2 \\
\hline
\end{tabular}

\subsection{SEM/EDS Analysis of the Composite}

The SEM morphology of the control sample of the RLDPE composite is shown in Plate 1. It can be observed from the micrograph that the RLDPE composite is fairly homogenous. This is because there is no addition of the 
reinforcer (particulate cow bone). This explains the low strength associated with the RLDPE composite. From Plate 2 and 3, the morphology of the micrographs shows the presence of reinforcer (particulate cow bone) in white parches fairly distributed within the matrix. The presence of the reinforcer increased the dislocation density of the RLDPE composite and this is responsible for the increase in strength observed for the RLDPE composite as the percentage of the reinforcer (particulate cow bone) increased from $10 \%$ particulate cow bone in Plate 2 to $25 \%$ in Plate 3. Also, the observed increase in strength and hardness value can be attributed to fairly good interfacial bonding between the hydrophobic matrix and the hydrophilic particulate cow bone which was achieved during compounding of the composites.
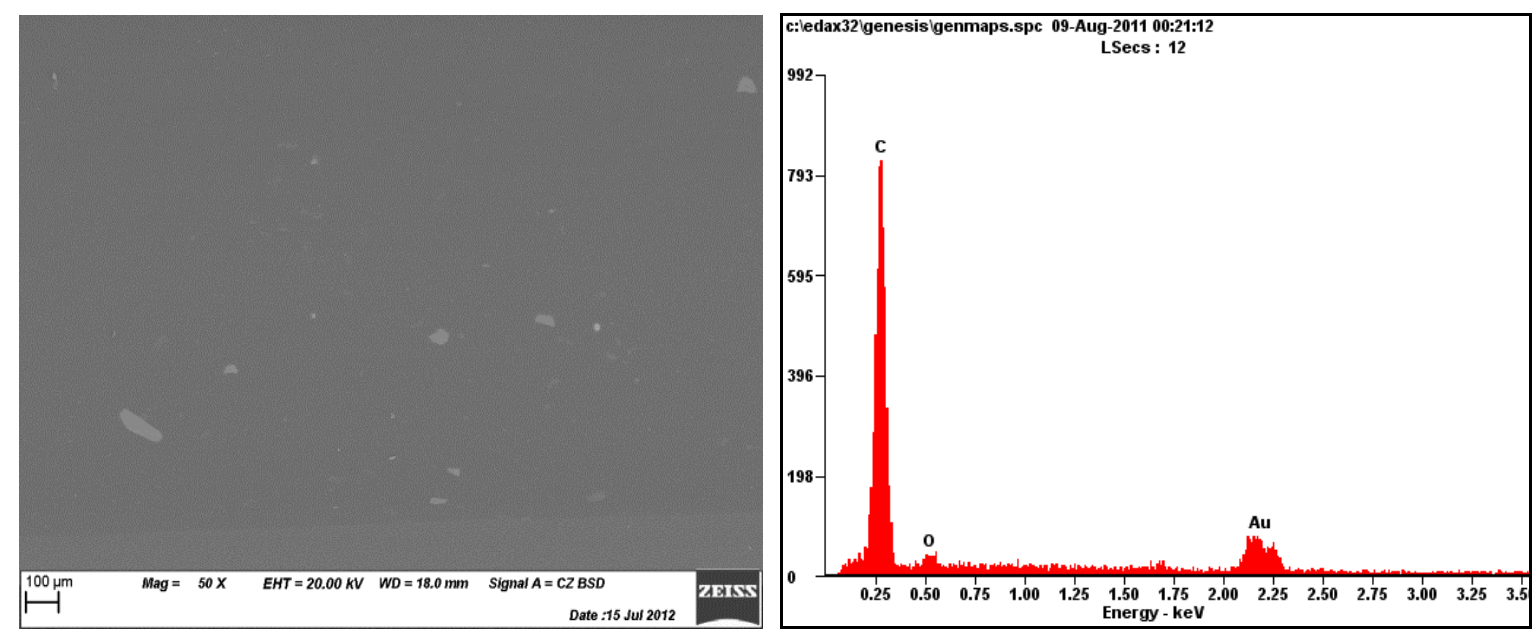

Plate 1. SEM/EDS Microstructure for the control sample of RLDPE composite
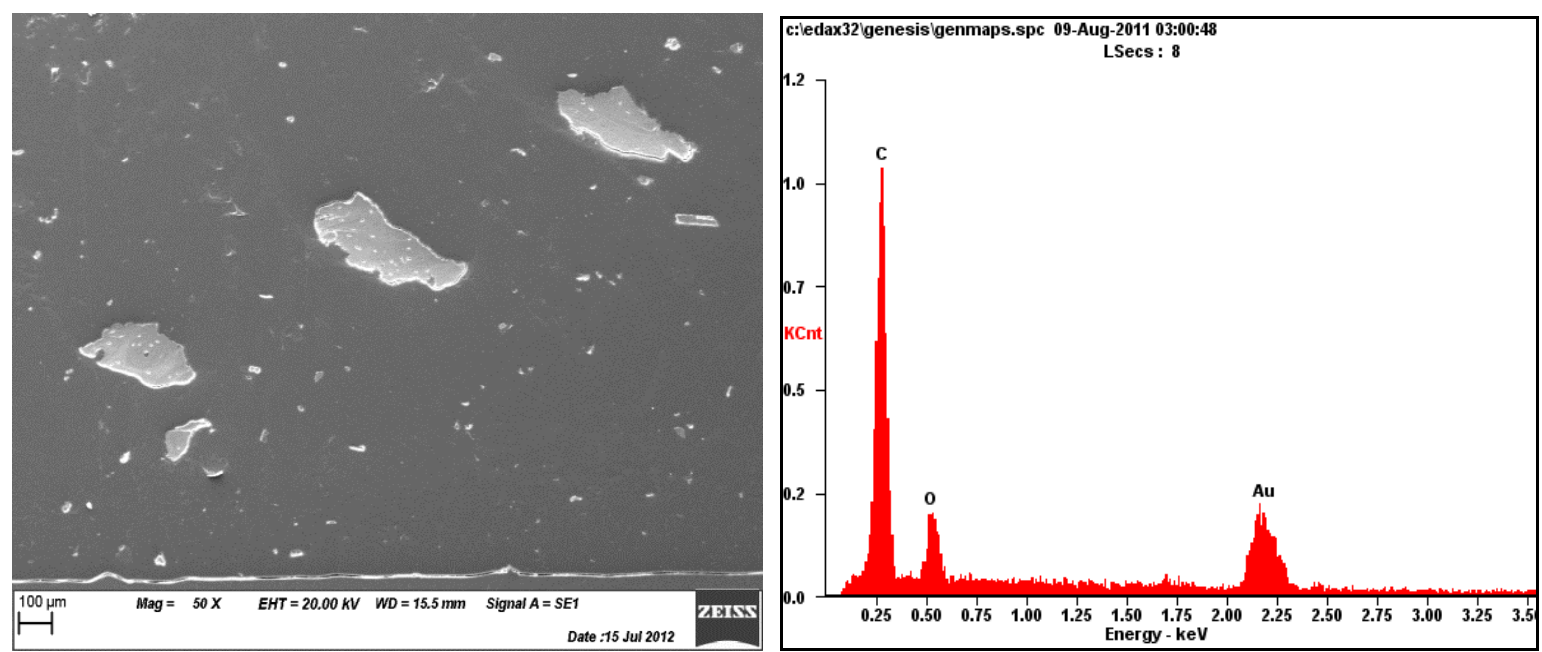

Plate 2. SEM/EDS of Microstructure of RLDPE with $15 \mathrm{wt} \%$ cow bone particles 

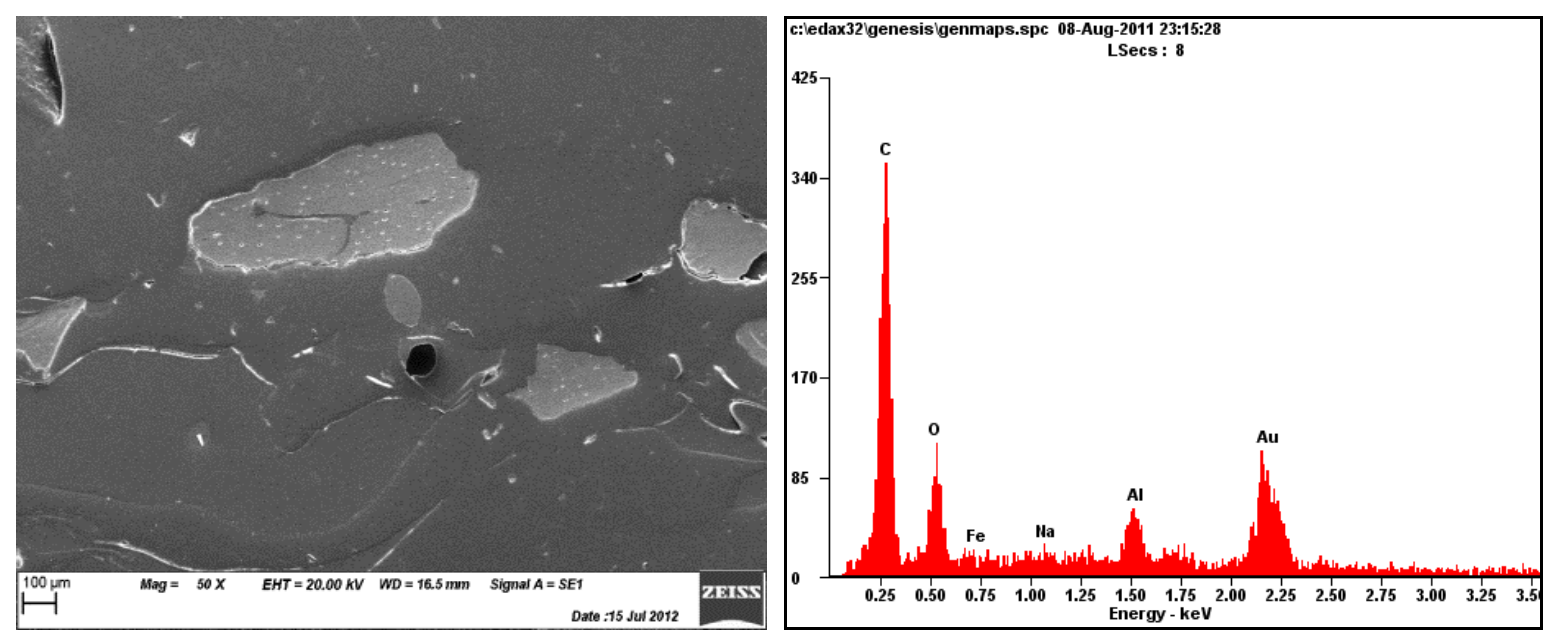

Plate 3. SEM/EDS of Microstructure of RLDPE with $25 \mathrm{wt} \%$ of cow bone particles

The decrease in toughness can be explained from the properties of the matrix and the reinforcer. The matrix is softer and the reinforcer is harder. There is a transfer of stress from the reinforcer to the matrix. It is presumed that the transfer of stress within the composite is due to the fairly good interfacial bonding between the matrix and the reinforcer.

\subsection{Wear Characterisation}

The results obtained for the wear rate of the RLDPE composites are shown in Table 6. From the results there is considerable reduction in the wear rate of the RLDPE composites with the addition of particulate cow bone. e.g wear rate for the RLDPE matrix ranges from $0.0117 \mathrm{~g}$ to $0.0267 \mathrm{~g}$ at $0 \%$ particulate cow-bone additions, while the values for the RLDPE composites were in the neighbourhood of $0.0027-0.0099 \mathrm{~g}$ at $25 \%$ particulate cow-bone additions. The decrease in wear rate of the composite can be attributed to the higher load bearing capacity of hard reinforcing material and better interfacial bond between the particle and the matrix reducing the possibility of particle pull out which may result in higher wear rate. At lower value of the load, sliding speed account for lower wear rate (Table 6). At higher load and time, the samples get well spread with lesser particles getting exposed and breakage of cow-bone particles takes place which is attributed to the extensive loss of the material due to fragmentation of cow-bone and their detachment from the test material due to the non-availability of a medium to hold them. The beneficial effect of the reinforcement on the wear resistance of the RLDPE composites is observed to be the best at low load and reduces with increase in applied load applied. With higher load contact temperatures becomes high and plastic deformation occurs with consequence of very high wear. When applied load are increased seizure was accompanied by a sudden increase in wear rate, heavy noise and vibration were also noticed. This type of seizure has been referred to as galling seizure (Suresha et al., 2004). Also, with increased load, friction and wear will increase due to critical surface energy of the polymer. This is explained as the frictional raised the temperature of the friction surface lead to relaxation of polymer molecule chains (Suresha et al., 2004).

For all composites tested in this investigation and within the speed range of $1.18-2.36 \mathrm{~m} / \mathrm{s}$ and a time of $60-120$ seconds, speed has significant effect on the wear of the composite. This may be attributed to the micro thermal softening effect of the matrix material which lowers the bonding effect of the reinforced particle (Suresha et al., 2004). 
Table 6. Result of wear characterisation of the RLDPE composites

\begin{tabular}{lllll}
\hline $\begin{array}{l}\text { Speed } \\
(\mathrm{m} / \mathrm{s})\end{array}$ & $\begin{array}{l}\text { Time } \\
(\mathrm{s})\end{array}$ & $\begin{array}{l}\text { Load } \\
(\mathrm{N})\end{array}$ & $\begin{array}{c}\text { Wear rate }(\mathrm{g}) \\
\text { at } 0 \%\end{array}$ & $\begin{array}{c}\text { Wear rate(g) } \\
\text { at } 25 \%\end{array}$ \\
\hline 1.18 & 60 & 10 & 0.0117 & 0.0027 \\
1.18 & 120 & 10 & 0.0086 & 0.0079 \\
1.18 & 60 & 15 & 0.0062 & 0.0037 \\
1.18 & 120 & 15 & 0.0052 & 0.0070 \\
2.36 & 60 & 10 & 0.0457 & 0.0058 \\
2.36 & 120 & 10 & 0.0309 & 0.0046 \\
2.36 & 60 & 15 & 0.0251 & 0.0056 \\
2.36 & 120 & 15 & 0.0267 & 0.0099 \\
\hline
\end{tabular}

The final linear regression equation for the wear rate of the cow bone reinforced RLDPE composite when tested against a pin on disc set up can be expressed as follows:

Wear $=0.016+0.004862 S s-0.005913 L a+0.006613 R r-0.007713 S s T t-0.002062 S s L a+0.001263 S s R r$

Substituting the coded values of the variables for any experimental condition in Equation 5, the wear rate for the RLDPE and its composite can be calculated. The $\beta_{0}=0.016$ in Equations 5 represent the values of the variables at the base level. The actual values and the predicted values of the wear rate are shown in Figure 5.

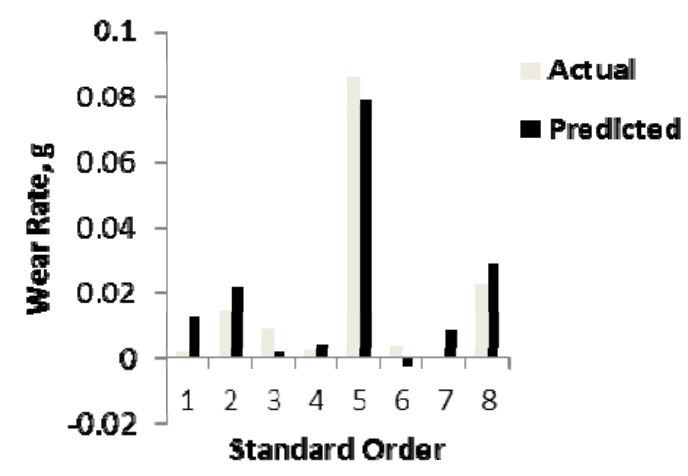

Figure 5. Comparison of actual and predicted model values results

It is evident from Figure 5 that the actual values are in well agreement with the predicted values. The results are in par with the earlier work of (Aigbodion et al., 2011). The regression coefficients associated with the variable i.e., sliding speed is positive which indicate that wear rate increases with increasing sliding speed. In line with above explanation, the effectiveness of material removal increases with increasing sliding speed due to increasing depth of indentation and cutting efficiency (Aigbodion et al., 2011).

The analysis of variance was used to investigate which design parameters significantly affect the wear characteristic. It was accomplished by separating the total variability of the wear result, which is measured by sum of the squared deviations from the wear rate obtained, into contributions by each of the design parameters and the errors. Examination of the calculated values of Fishers (F) for all control factors also showed a very high influence of the cow-bone particles additions, applied load and sliding speed on wear rate of RLDPE composite (Tables 7). From Table 7, it can be observed that the additions of cow bone particles to RLDPE composites have the most significant effect on wear, followed by load and sliding speed respectively, while time has no significant effect. 
Table 7. Analysis of Variance table to identify significant factors influencing wear rate of the composites.

\begin{tabular}{cccccc}
\hline Source & $\begin{array}{c}\text { Sum of } \\
\text { Square }\end{array}$ & DF & $\begin{array}{c}\text { Mean } \\
\text { Squares }\end{array}$ & $\begin{array}{c}\text { F } \\
\text { Value }\end{array}$ & Prob $>$ F \\
\hline Model & 0.001341 & 6 & 0.0002235 & 16.22 & $\begin{array}{c}0.1878 \text { not } \\
\text { significant }\end{array}$ \\
Ss & 0.0001892 & 1 & 0.0001892 & 13.73 & 0.1678 \\
La & 0.0002797 & 1 & 0.0002797 & 20.29 & 0.1391 \\
Rr & 0.0003498 & 1 & 0.0003498 & 25.38 & 0.1247 \\
SsTt & 0.0004759 & 1 & 0.0004759 & 34.53 & 0.1073 \\
Ssld & 0.00003403 & 1 & 0.00003403 & 2.47 & 0.3608 \\
SsRr & 0.00001275 & 1 & 0.00001275 & 0.93 & 0.5124 \\
Residual & 0.00001378 & 1 & 0.00001378 & & \\
Cor Total & 0.001355 & 7 & & & \\
\hline
\end{tabular}

From this statistical analysis, the cow-bone particles, sliding speed and load all affect the wear behaviour of the composites. The interactions effect of sliding speed-time also shows significant effect on the composites. The "Model F-value" of 16.22 implies the model is not significant relative to the noise. There is $18.78 \%$ chance that a "Model F-value" this large could occur due to noise. Value of "Prob F" less than 0.0500 indicate model terms are significant. This model can be used to navigate the design space.

\section{Conclusions}

From the result of the investigations and discussion, the following conclusions have been made:

1) The uniform distribution of cow bone particles in the microstructure of the cow bone reinforced RLDPE composite is the major factor responsible for the increase and improvement in strength.

2) Reduced porosity was observed with increasing amount of reinforcement.

3) Effect of variables i.e., load and sliding speed is more pronounced on the wear of the composite rather than time.

4) Factorial design of the experiment can be successfully employed to describe the wear behaviour of the samples and the developed linear equation models can be used in predicting the wear rate of the materials within the selected experimental conditions.

\section{References}

Aigbodion, V. S., Hassan, S. B., \& Agunsoye, J. O. (2011). Effect of ash reinforcement on dry sliding wear behaviour of polymer matrix composites. Materials and Design, 33, 322-327. http://dx.doi.org/10.1016/j.matdes.2011.07.002

Anil, A., \& Ali, S. (2010). Material Characterisation of Extrusion Compounded Polymer Composites with Different Dimensioned Wood Additives. International Journal of Arts and Sciences, 3(9), 314-319.

Bahadur, S., \& Gong, D. (1992). The role of copper compounds as filler in the transfer and wear behaviour of polyetheretherketone. Wear, 154, 151-156. http://dx.doi.org/10.1016/0043-1648(92)90251-3

Briscoe, B., Yoo, L. H., \& Stolarski, T. A. (1986). The friction and wear of poly (tetrafluorethylene)-poly(etherketone) composites: an initial appraisal of the optimum composition. Wear, 108, 357-74. http://dx.doi.org/10.1016/0043-1648(86)90013-X

Dhingra, A. K. (1986). Metal Replacement by Composite. JOM., 38(3), 17. http://dx.doi.org/10.1007/BF03257887

Friedrich, K. (1986). Friction and wear of polymer composites (p. 233). In K. Friedrich (Ed.). Amsterdam: Elsevier. http://dx.doi.org/10.1016/B978-0-444-42524-9.50012-0

Michael, I. O., Muneer, U., \& Friday, A. O. (2012). Mechanical Properties of Rice Husk Fiiled Cashew Nut Shell Liquid Resin Composites. Journal of Materials Science Research, 1(4), 89-97. http://dx.doi.org/10.5539/jmsr.v1n4p8 
Mohanty, A. K., Misra, M, \& Hinrichsen, G. (2000). Biofibres, biodegradable polymers and biocomposites: An overview. Eng. Macromol Mater., 276-277, 1-24.

Pihtili, H., \& Tosun, N. (2002). Investigation of the wear behaviour of glass fibre-reinforced composite and plain $\begin{array}{lllll}\text { polyster resin. } & \text { Composite } & \text { Science }\end{array}$ http://dx.doi.org/10.1016/S0266-3538(01)00196-8

Saira, T., Munawar, A., \& Shafiullah, K. (2007). Natural Fiber-Reinforced Polymer Composites. Proc. Pakistan Acad. Sci., 4(2), 129-144.

Suresha, B., \& Chandramohan, G. (2004). Friction and wear characteristic of carbonepoxy and glass epoxy oven roving fiber composites. Journal of Reinf Plastic Composite, 64, 67-72.

Voss, H, \& Friedrich, K. (1985). The wear behavior of short fiber reinforced thermoplastics sliding against smooth steel surfaces. Wear of Materials (pp. 742-750). New York: ASME.

Wang, Q., Xue, Q., Liu, H., Shen, W., \& Xu, J. (1996). The effect of nanometre on $\mathrm{ZrO}_{2}$ on the tribological behaviour of PEEK. Wear, 198, 216-219. http://dx.doi.org/10.1016/0043-1648(96)07201-8

Weston, J. W., Russ, G. M., \& Wei, H. Z. (2010). Improved Wear and Mechanical Properties of UHMWPE-Carbon Nanofiber Composites thorough an Optimised Paraffin-Assisted Melt-Mixing Process. Composite Part B: Engineering, 4(3), 584-591. 